\title{
Techniques for Predicting Exposures to Polycyclic Aromatic Hydrocarbons (PAHs) Emitted from Cooking Processes for Cooking Workers
}

\author{
Chun-Yu Chen ${ }^{1}$, Yu-Chieh Kuo ${ }^{1}$, Shih-Min Wang ${ }^{2}$, Kua-Rong Wu ${ }^{1}$, Yu-Cheng Chen ${ }^{3}$, \\ Perng-Jy Tsai ${ }^{1 *}$ \\ ${ }^{1}$ Department of Environmental and Occupational Health, College of Medicine, National Cheng Kung University, Tainan \\ 70403, Taiwan \\ ${ }^{2}$ Department of Safety, Health and Environmental Engineering, Ming Chi University of Technology, New Taipei 24301, \\ Taiwan \\ ${ }^{3}$ National Environmental Health Research Center, National Health Research Institutes, Miaoli 35053, Taiwan
}

\begin{abstract}
Cooking oil fumes contain polycyclic aromatic hydrocarbons (PAHs), which are known to cause chronic human health effects; hence long-term exposure data is required for determining workers' exposure profiles and the resultant health risks. However, due to both time and cost constraints, previous studies were performed on a cross-sectional basis. To date, mathematical models have been widely used for predicting long-term exposures in the industrial hygiene field. The aims of this study were to develop suitable predictive models for establishing long-term exposure data on cooking workers. The whole study was conducted in a test chamber with an exhaust hood installed $0.7 \mathrm{~m}$ above a deep-frying pan and operated at flow rates of 2.64-5.16 $\mathrm{m}^{3} \mathrm{~min}^{-1}$. The cooking process that we selected for testing used peanut oil to deep-fry chicken nuggets at $200^{\circ} \mathrm{C}$. An IOM inhalable sampler and an XAD-2 tube were successively used to collect particle- and gas-phase PAHs, respectively. All of the collected samples were analyzed for 21 PAHs using a gas chromatograph (GC) with tandem mass spectrometry (MS/MS). The results showed that the emission rates of the total-PAHs in the gas-phase and the particle-phase were $1.45 \times 10^{4}$ and $2.14 \times 10^{2} \mathrm{ng} \mathrm{min}^{-1}$, respectively. The capture efficiencies of the exhaust hood for the total-PAHs were $39.1-76.5 \%$. The resultant fugitive emission rates of the gas-phase and the particle-phase ranged from $3.41 \times 10^{3}$ to $8.82 \times 10^{3}$ and from $5.03 \times 10^{1}$ to $1.30 \times 10^{2} \mathrm{ng} \mathrm{min}^{-1}$, respectively. As no significant difference in the sampling results of the total-PAHs was detected between the chef-zone (i.e., the near zone) and the helper-zone (i.e., the far zone), the well-mixed room (WMR) model was adopted for estimating the exposures of all workers. A good correlation $\left(y=0.134 x+75.3 ; R^{2}=0.860\right)$ was found between the model predicted results $\left(x ; 3.25 \times 10^{2}-1.57 \times 10^{3} \mathrm{ng}^{m^{-1}}\right)^{-1}$ and the field sampling results $\left(\mathrm{y} ; 1.36 \times 10^{2}-2.92 \times 10^{2} \mathrm{ng} \mathrm{min}^{-1}\right.$ ), indicating the plausibility of using the proposed approach to establish a long-term exposure databank for the cooking industry.
\end{abstract}

Keywords: Cooking fumes; Polycyclic aromatic hydrocarbons; Exposure assessment; Model prediction.

\section{INTRODUCTION}

Cooking fumes are known as one of the most significant indoor air pollution sources containing complex chemical compounds, including particulate matter, volatile organic compounds (VOCs), aromatic amines, polycyclic aromatic hydrocarbons (PAHs), etc. (Abdullahi et al., 2013). Many studies have been conducted to investigate the emission rate of cooking-generated particles (Gao et al., 2013), emissions of particles from cooking exhaust (Mi et al., 2014), and chemical characteristics of particles of various cooking

\footnotetext{
${ }^{*}$ Corresponding author.

E-mail address: pjtsai@mail.ncku.edu.tw
}

styles (Wang et al., 2015). For PAH emissions from cooking sources, previous studies indicate that they could be emitted into the workplace environment when the cooking oil was heated between 180 and $270^{\circ} \mathrm{C}$ (Siegmann and Sattler, 1996; Zhu and Wang, 2003; Purcaro et al., 2006). Cooking methods involved in the use of the cooking oil, such as stir-frying, panfrying and deep-frying, generated more PAHs than those of water, such as boiling and steaming. In particular, the deep-frying process usually produces the highest PAHs as in comparison with other cooking methods (See and Balasubramanian, 2006, 2008), Chinese cooking methods generate higher levels of benzo $[a]$ pyrene than that of the Western and Japanese restaurant (Li et al., 2003), and fiveand six-ringed PAHs were predominant in the composition of particles emitted from night market sources (Zhang et al., 2015). PAH compounds such as benzo[a]pyrene has been 
proved to be carcinogenic (Culp et al., 1998), and hightemperature frying oil fume has been classified into Group 2A (IARC, 2010).

Previous PAH exposure studies indicated that the naphthalene was the dominant compound (the breathing zone exposure concentrations $=0.15-0.27 \mu \mathrm{g} \mathrm{m}^{-3}$ ) during the beefsteak pan-frying process (Sjaastad et al., 2010). Benzo $[a]$ pyrene concentrations fell to the range of 6$24 \mathrm{ng} \mathrm{m}^{-3}$ and $150-440 \mathrm{ng} \mathrm{m}^{-3}$ for home and commercial kitchens, respectively (Zhu and Wang, 2003). Although many PAH exposure assessment studies have been conducted, most of them were on the cross-sectional basis due to the cost constraints in both samplings and sample analyses. However, considering the chronic health effect of PAHs, the establishment of a long-term exposure data bank is needed for conducting exposure and health risk assessments.

To date, mathematical models have been widely used for predicting pollutant concentrations in the industrial hygiene field, particularly both the well-mixed room model and near-field (NF)/far-field (FF) model have been used in indoor environments with known dimensions, ventilation rates, and pollutant generation rates. For example, Nicas et al. (2006) used the near-field/far-field model to estimate benzene exposures, and a high $\mathrm{R}^{2}(0.94)$ was obtained for predicting exposure of both fields. Gaffney et al. (2008) used both well-mixed room model and near-field/far-field model to estimate methanol exposure concentrations in a semiconductor manufacturing setting, better predictions were obtained from the latter than the former. In principle, if modeling results and measured concentrations had a good correlation, then obtaining a large amount of longterm exposure data might become possible even without conducting field measurements (AIHA, 2009; Kim et al., 2009).

For cooking processes, both the well-mixed room model and near-field/far-field model have never been used for predicting workers' PAH exposures. Though workplace dimensions are usually available, the generated cooking fumes are known inherent with upward thermal drafting forces which might lead to the stratification of pollutant concentrations at different heights (Li and Delsante, 1996). In addition, considering the installation of ventilation (i.e., the exhaust hood), cooking fume emission rates should be replaced by the fugitive emission rates (i.e., should take the capture efficiencies of the exhaust hood into account) before model predictions. Therefore, the feasibility of using both the well-mixed room model and near-field/farfield model for predicting exposures of PAHs emitted from cooking processes requires further investigation.

The present study was conducted in a test room installed with a deep-frying apparatus and an exhaust hood with adjustable ventilation rate for a fixed cooking process (temperature and time, etc.). Emission rates of PAHs were measured, hood capture efficiencies were calculated, and resultant fugitive emission rates were estimated. Concentrations obtained from both the well-mixed room model and near-field/far-field model were predicted and compared with the measured values. Finally, the feasibilities of both models were assessed, and techniques for predicting exposures of PAHs emitted from cooking processes were proposed. The results obtained from the present study would be helpful for cooking industries to establish long-term $\mathrm{PAH}$ exposure data for conducting exposure and health risk assessments.

\section{MATERIALS AND METHODS}

\section{Test Room and Test Cooking Condition}

All experiments were conducted in a test room $(\mathrm{L} \times \mathrm{W} \times$ $\mathrm{H}=3.25 \mathrm{~m} \times 3.10 \mathrm{~m} \times 2.75 \mathrm{~m})$ with a general kitchen settings (Chiang et al., 1998) including an electronic deepfrying machine $(2000 \mathrm{~W}, \mathrm{~L} \times \mathrm{W}=30 \mathrm{~cm} \times 15.3 \mathrm{~cm}$; WFT-4L, WISE Inc., Taipei, Taiwan) with a cooking surface $1.1 \mathrm{~m}$ above the floor, and a kitchen exhaust hood $(\mathrm{L} \times \mathrm{W}=89 \mathrm{~cm} \times$ $52 \mathrm{~cm}$; DR-7790ASXL, Sakura Corp., Taichung, Taiwan) placed at $0.7 \mathrm{~m}$ above from the deep-frying machine (i.e., $1.8 \mathrm{~m}$ above the floor). For each deep-frying test run, it contains 9 repeated cycles, and each cycle includes a 5-min deep-frying period, and followed by a 5 -min rest (i.e., the whole test run lasts for 90 minutes). During each deepfrying period, $300 \mathrm{~g}$ fresh chicken nuggets were deep-fried at $200^{\circ} \mathrm{C}$ in $3 \mathrm{~L}$ peanut oil. The cooking oil was repeated used for the whole test run. Three default flow rates of the exhaust hood (i.e., low, medium, and high $=2.64,3.69$, and $5.16 \mathrm{~m}^{3} \mathrm{~min}^{-1}$, respectively) were selected in the present study. The only door and window of the test room were closed during the experiment period.

\section{Sampling for PAH Emission Rates and Exposure Concentrations}

For each selected ventilation rate, three test runs were conducted to determine its PAH emission rate $(\mathrm{G})$ and resultant exposure concentrations inside the test room. For sampling the emission rate, the test system (including the electronic deep-frying machine and the exhaust hood) was enclosed completely to ensure the non-releasing of emitted PAHs, and a sampling train was placed $15 \mathrm{~cm}$ beneath the exhaust hood (Fig. 1), which includes an IOM personal inhalable sampler (Cat. No. 225-70A, SKC Inc., MN, USA) with a quartz fiber filter for collecting particle-phase PAHs, and followed by an XAD-2 tube (Amberlite ${ }^{\circledR} \mathrm{XAD}^{\circledR}-2$, Sigma-Aldrich Corp., MO, USA) for collecting gas-phase PAHs.

Exposure concentrations of PAHs inside the test room were measured using the same sampling train but placed on a mannequin. Samples were collected from both sites of the chef-zone (CZ) (1.5 m in height above the floor, and $0.5 \mathrm{~m}$ away from the deep-frying machine to represent the exposure of chefs), and the helper-zone (HZ) $(1.5 \mathrm{~m}$ in height above the floor, and $1.5 \mathrm{~m}$ away from the deepfrying machine to represent the exposures of chefs' helpers) (Fig. 2).

\section{PAH Analysis}

In the present study, each collected filter was microwave extracted using a mixed solvent (n-hexane and dichloromethane, $\mathrm{V}: \mathrm{V}=1: 1,25 \mathrm{~mL}$ ) for $1 \mathrm{hr}$. For each collected XAD-2 sample, it was extracted using ultrasonic 


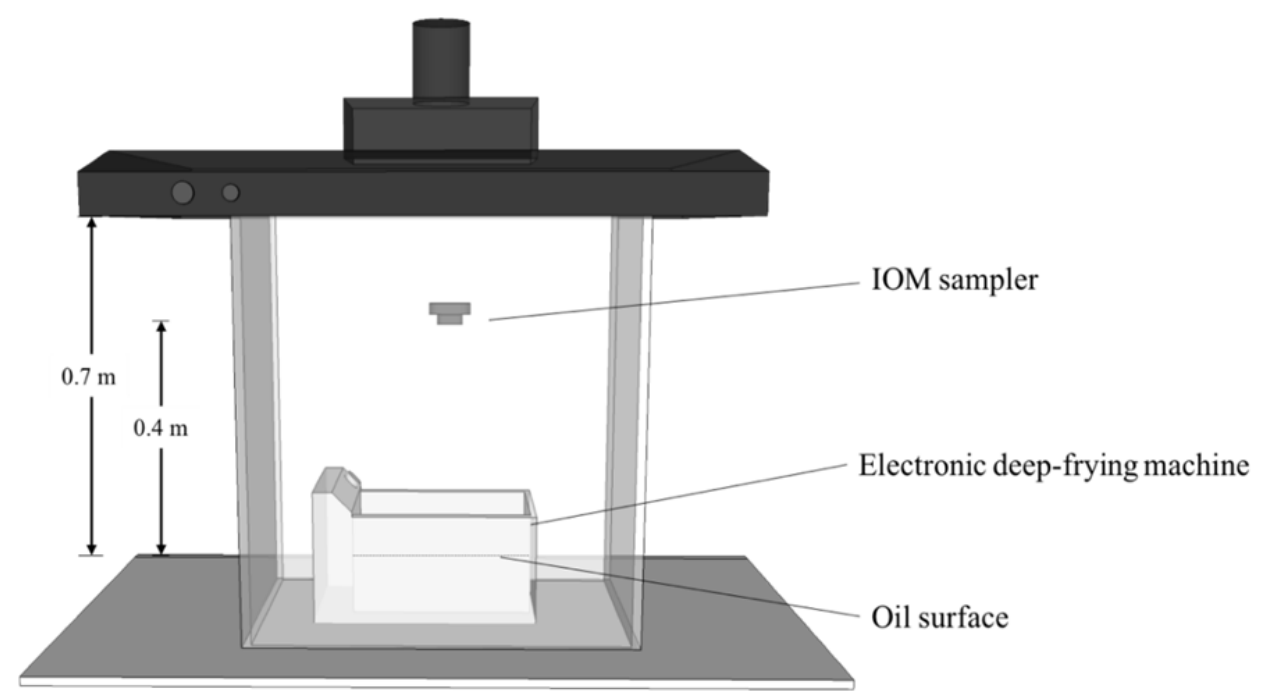

Fig. 1. Schematic of the site for placing IOM sampler for determining PAH emission rates when the exhaust hood and deep frying machine are in an enclosure condition.

bath with $2 \mathrm{~mL}$ dichloromethane (DCM) for $1 \mathrm{hr}$ (one cycle for 15-min ultrasonic bath followed by 5-min rest, and repeated continuously for three cycles). The extracted samples were then concentrated to $\sim 5 \mathrm{~mL}$, and cleaned up using the YMC silica gel tube $\left(\mathrm{NH}_{2} 12 \mathrm{~g}, 50 \mu \mathrm{m}\right.$; YMCDispoPackAT, YMC Co., Ltd., Kyoto, Japan) to ensure no oil was present in the samples. Then, the above samples were re-concentrated and diluted to exactly $1.0 \mathrm{~mL}$. The PAH content was determined using a gas chromatograph (GC) (Agilent 7890B, Agilent Technologies Inc., CA, USA) with tandem mass spectrometry (MS/MS) (Agilent 7000C MS/MS Triple Quad, Agilent Technologies Inc., CA, USA) and a computer workstation. This GC/MS/MS was equipped with an Agilent 122-9632 DB-EUPAH column (30 m [length] $\times 0.32 \mathrm{~mm}$ [I.D.], film thickness $=0.25 \mu \mathrm{m})($ Agilent 1229632 DB-EUPAH, Agilent Technologies Inc., CA, USA) and an Agilent 7693 automatic sampler (Agilent 7693, Agilent Technologies Inc., CA, USA) and was operated under the following conditions: injection volume $10 \mu \mathrm{L}$; splitless injection at $310^{\circ} \mathrm{C}$; ion sources temperature at $310^{\circ} \mathrm{C}$; and oven from $80^{\circ} \mathrm{C}$ to $200^{\circ} \mathrm{C}$ at $20^{\circ} \mathrm{C} \mathrm{min}^{-1}, 200^{\circ} \mathrm{C}$ to $355^{\circ} \mathrm{C}$ at $8^{\circ} \mathrm{C} \mathrm{min}{ }^{-1}$, hold at $355^{\circ} \mathrm{C}$ for $17.325 \mathrm{~min}$. The masses of primary and secondary ions of PAHs were determined with the scan mode for pure PAH standards. Qualification of PAHs was performed using the selected ion monitoring (SIM) mode.

The concentrations of 21 PAH species were determined, including naphthalene (Nap), acenaphthylene (AcPy), acenaphthene (Acp), fluorene (Flu), phenanthrene (PA), anthracene (Ant), fluoranthene (FL), pyearene (Pyear), cyclopenta $[c, d]$ pyearene $(\mathrm{CYC}), \quad$ benzo $[a]$ anthracene $(\mathrm{BaA})$, chrysene $(\mathrm{CHR})$, benzo[b]fluoranthene $(\mathrm{BbF})$, benzo $[k]$ fluoranthene $(\mathrm{BkF})$, benzo[e]pyearene $(\mathrm{BeP})$, benzo $[a]$ pyearene $(\mathrm{BaP})$, perylene (PER), indeno[1,2,3$c d$ pyearene (IND), dibenzo[ $a, h]$ anthracene (DBA), benzo $[b]$ chrycene $(\mathrm{BbC})$, benzo $[$ ghi $]$ perylene (BghiP), and coronene (COR). The GC/MS/MS was calibrated with a diluted standard solution of $16 \mathrm{PAH}$ compounds (PAH
Mixture-610M, Supleco) plus 5 additional individual PAHs obtained from Merck. Analysis of serial dilutions of PAH standards showed the detection limit of GC/MS/MS falling to the range from 0.06 to $0.45 \mathrm{ppb}$ for the analyzed $21 \mathrm{PAH}$ compounds. Ten consecutive injections of a PAH 610-M standard yielded an average relative standard deviation (RSD) of GC/MS integration area of 3.0\% with a range of $0.8-5.1 \%$. Quality control (QC) samples adopted the median level of the low calibration curve $(30 \mathrm{ppb})$, and were analyzed along with each batch. The QC results were required to fall within $\pm 20 \%$ of the calibration curve. To evaluate analytical precision, one spike sample and one random replicate sample were analyzed for each batch. Recovery efficiencies were determined using a solution containing known PAH concentrations following the same experimental procedures used for the treatment of samples. This study showed recovery efficiencies for the 21 PAH compounds ranging from $65.0 \%$ to $117.5 \%$, with an average value of $90.9 \%$. Analysis of field blanks and method blanks, including the glass fiber filter and XAD-2 cartridge, found no significant contamination (GC/MS/MS integrated area $<$ detection limit).

\section{Data Analysis}

In this study, the total-PAH concentration were regarded as the sum of the concentrations of $21 \mathrm{PAH}$ compounds for each collected sample. In order to assess the PAH homolog distribution for each collected sample, the total-PAH were further classified into three categories, including the low molecular weight PAHs (LMW-PAHs, containing 2- to 3ringed PAHs), middle molecular weight PAHs (MMW-PAHs, containing 4-ringed PAHs), and high molecular weight PAHs (HMW-PAHs, containing 5- to 7-ringed PAHs). Moreover, considering that several PAH compounds have been found to be human carcinogens, the carcinogenic potencies associated with PAHs emissions from each emission source were also determined. In principle, the carcinogenic potency of a given $\mathrm{PAH}$ compound can be assessed based on its 

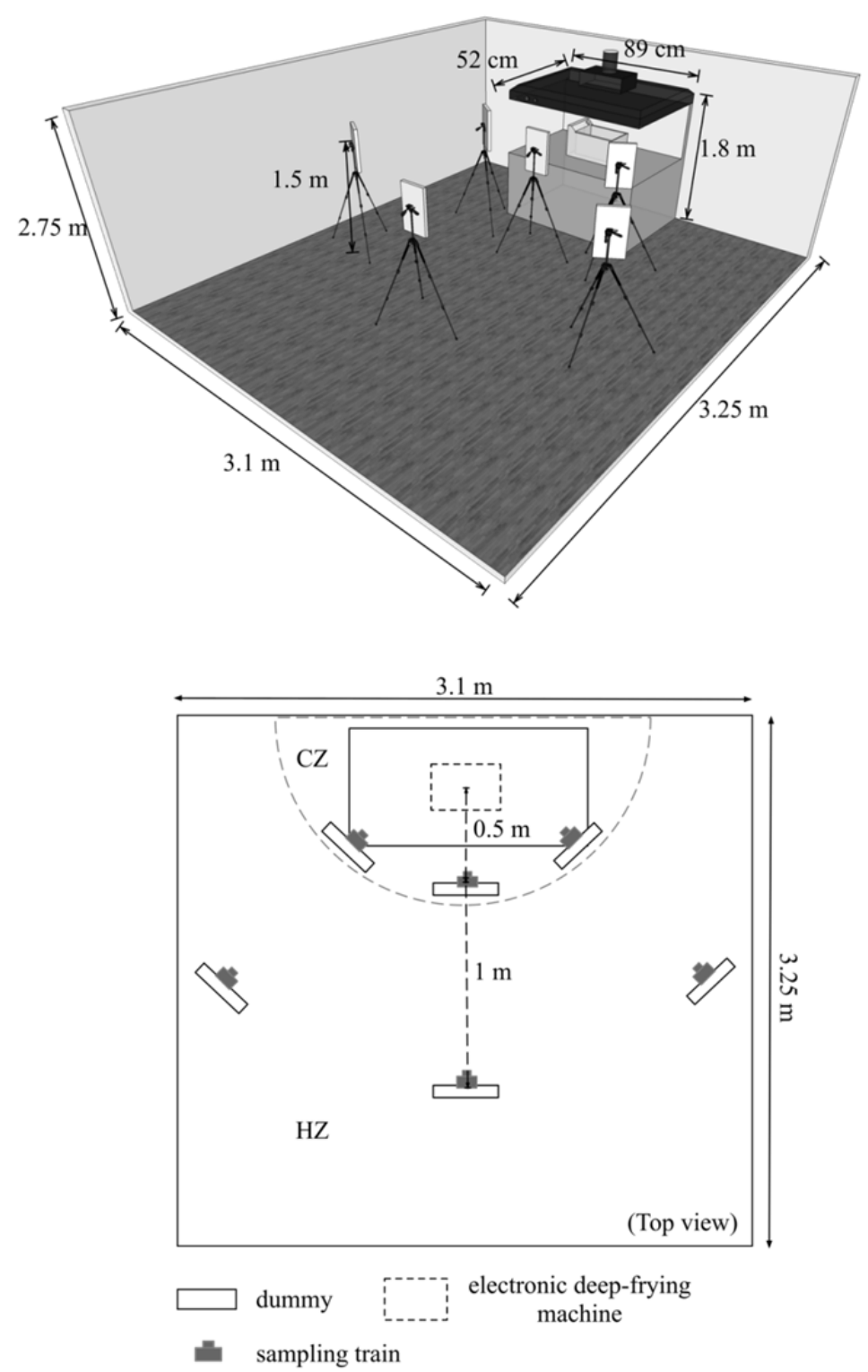

Fig. 2. Schematic of sites for collecting near-field and far-field PAH exposure concentrations.

benzo $[a]$ pyearene equivalent concentration (i.e., $\mathrm{BaP}_{\mathrm{eq}}$ ). Calculation of the $\mathrm{BaP}_{\text {eq }}$ concentration for a given $\mathrm{PAH}$ compound requires the use of the toxic equivalent factor (TEF), which represents the relative carcinogenic potency of the given PAH compound by reference to the specific compound $\mathrm{BaP}$, to adjust its original concentration. To date, several proposals for TEFs (Nisbet and LaGoy, 1992; Malcolm and Dobson, 1994; Larsen and Larsen, 1998) are used in the present study (Table 1). On the basis of this TEF list, the carcinogenic potency of the total-PAHs (i.e., the total- $\mathrm{BaP}_{\mathrm{eq}}$ ) could be assessed using Eq. (1):

Total $-B a P_{e q}=\sum_{i=1}^{21} P A H_{i} \times T E F_{i}$.

where $P A H_{i}$ and $T E F_{i}$ are the concentration of the $i^{\text {th }} \mathrm{PAH}$ compound and its TEF, respectively.

\section{Determining Capture Efficiencies of the Exhaust Hood} and Fugitive Emission Rates

For the purpose of estimating exposures of cooking workers, PAH emission rates $(\mathrm{G})$ of the investigated cooking process should be replaced by the fugitive emission rates $\left(\mathrm{ER}_{\mathrm{f}}\right)$. Assuming the capture efficiencies $(\varepsilon ; \%)$ of the exhaust hood is known, then $\mathrm{ER}_{\mathrm{f}}$ can be obtained using the following equation:

$\mathrm{ER}_{\mathrm{f}}=\mathrm{G} \times((100-\varepsilon) \%$

In principle, the high temperature will lead to a thermal draft with an upward air current during cooking processes. As the heated air rises, it mixes turbulently with the surrounding air. This results in an increasing air plume diameter and volumetric flow rates. The plume flow rate of the thermal draft at the hood entry level can be estimated as the following equation (Popiołek et al., 1998): 
Table 1. The studied 21 PAH compounds and their TEFs proposed by Larsen and Larsen (1998), Malcolm and Dobson (1994), Nisbet and LaGoy (1992), and those adopted in the present study.

\begin{tabular}{lllll}
\hline PAHs & (Larsen and Larsen, 1998) & (Malcolm and Dobson, 1994) & (Nisbet and LaGoy, 1992) & This study \\
\hline NaP & - & 0.001 & 0.001 & 0.001 \\
AcPy & - & 0.001 & 0.001 & 0.001 \\
Acp & - & 0.001 & 0.001 & 0.001 \\
Flu & 0.05 & 0.001 & 0.001 & 0.05 \\
PA & 0.0005 & 0.001 & 0.001 & 0.001 \\
Ant & 0.0005 & 0.01 & 0.01 & 0.01 \\
FL & - & 0.001 & 0.001 & 0.001 \\
Pyr & 0.001 & 0.001 & 0.001 & 0.001 \\
BaA & 0.005 & 0.1 & 0.1 \\
CHR & 0.03 & 0.01 & 0.01 & 0.03 \\
CYC & 0.02 & - & 0.1 \\
BbF & 0.1 & 0.1 & 0.1 & 0.1 \\
BkF & 0.1 & 0.1 & 0.1 \\
BeP & 0.002 & -1 & - & 0.002 \\
BaP & 1 & 0.1 & 1 & 1 \\
PER & - & 0.001 & - & 0.001 \\
DBA & 1 & 1 & 1 & 1 \\
IND & - & 0.001 & 0.1 & 0.1 \\
BbC & - & 1 & - & -1 \\
BghiP & 0.02 & 0.1 & 0.01 & 0.02 \\
COR & - & - & - & 0.001 \\
\hline
\end{tabular}

${ }^{a}$ No TEF has been suggested.

$\mathrm{Q}_{\mathrm{p}}=\mathrm{K}_{\mathrm{v}} \mathrm{E}^{1 / 3}(\mathrm{~h}+\mathrm{Z})^{5 / 3}$

where $Q_{p}$ is the plume flow rate at the hood entry level $\left(\mathrm{m}^{3} \mathrm{~s}^{-1}\right), \mathrm{E}$ is the heat source power $(\mathrm{W}), \mathrm{h}$ is the height from the heat source to the hood entry $(\mathrm{m}), \mathrm{Z}$ is the distance between the heat source and the origin point of the plume $(\mathrm{m})$, and $\mathrm{K}_{\mathrm{v}}$ is the coefficient describing the air entrainment by the plume. Here, $K_{v}$ and $Z$ were as suggested by Yik and $\mathrm{Au}$ (2002) to be 0.0065 and $2.25 \mathrm{D}$ for cooking processes, respectively. The capture efficiency $(\varepsilon)$ of gaseous pollutants emitted from the cooking process can be determined using Eq. (4):

$\varepsilon=\frac{\mathrm{q}_{\mathrm{f}}}{\mathrm{Q}_{\mathrm{p}}} \times 100 \%=\frac{\mathrm{q}_{\mathrm{f}}}{0.0065 \mathrm{E}^{1 / 3}(\mathrm{H}+2.25 \mathrm{D})^{5 / 3}} \times 100 \%$,

if $\mathrm{q}_{\mathrm{f}}>\mathrm{Q}_{\mathrm{p}}, \varepsilon=100 \%$,

where $\mathrm{q}_{\mathrm{f}}$ is the exhaust flow rate $\left(\mathrm{m}^{3} \mathrm{~s}^{-1}\right)$. Considering particle phase pollutants emitted from the cooking process were dominated by $\mathrm{PM}_{1}$ (Lunden et al., 2015), which suggests that their capture efficiencies could also be adopted for gas phase pollutants (i.e., Eq. (4)). Therefore, Eq. (4) was adopted for determining the capture efficiencies $(\varepsilon)$ for the total-PAHs, gas-phase PAHs, particle-phase PAHs, and total- $\mathrm{BaP}_{\mathrm{eq}}$ in the present study.

\section{The Selected Prediction Models}

In the present study, both the well-mixed room model and near-field/far-field model were selected for predicting workers' PAH exposures. Firstly, we assume that fugitive emissions will be mixed completely in the kitchen space instantly due to the limited kitchen space and strong mixing effect. Therefore, the obtained fugitive emission rates of PAHs $\left(\mathrm{ER}_{\mathrm{f}}\right)$ were applied to the well-mixed room model (Reinke and Keil, 2006) to predict the exposures of all workers in the test room (i.e., including chefs and their helpers, and assuming both share the same exposure level) using Eq. (5):

$$
C_{W M R}=\left(C_{0}-C_{i n}-\frac{E R_{f}}{Q}\right) e^{\frac{-Q\left(t-t_{0}\right)}{V}}+C_{i n}+\frac{E R_{f}}{Q}
$$

where $C_{W M R}$ is the concentration predicted for all workers at time $t, C_{0}$ is the concentration of test room at time $t_{0}, C_{i n}$ is the concentration of the inlet air, $Q$ is the inlet air flow rate, and $V$ is the volume of the test room. Secondly, we assume that fugitive emissions will affect more strongly on the exposure of workers who are closer than those of less close to the emission source. In this situation, the obtained fugitive emission rates of PAHs $\left(\mathrm{ER}_{\mathrm{f}}\right)$ were also applied to the near-field/far-field model (Nicas, 2006) to estimate the exposures of chefs (i.e., near-field exposures) and their helpers (i.e., far-field exposures) using Eqs. (6) and (7), respectively:

$$
\begin{aligned}
s C_{N F}= & \frac{E R_{f}}{Q}+\frac{E R_{f}}{\beta}+E R_{f}\left(\frac{\beta \cdot Q+\lambda_{2} \cdot V_{N}(\beta+Q)}{\beta \cdot Q \cdot V_{N}\left(\lambda_{1}+\lambda_{2}\right)}\right) e^{\lambda_{1} \cdot t} \\
& -E R_{f}\left(\frac{\beta \cdot Q+\lambda_{1} \cdot V_{N}(\beta+Q)}{\beta \cdot Q \cdot V_{N}\left(\lambda_{1}-\lambda_{2}\right)}\right) e^{\lambda_{2} \cdot t},
\end{aligned}
$$




$$
\begin{aligned}
C_{F F}= & \frac{E R_{f}}{Q} \\
& +E R_{f}\left(\frac{\lambda_{1} \cdot V_{N}+\beta}{\beta}\right)\left(\frac{\beta \cdot Q+\lambda_{2} \cdot V_{N}(\beta+Q)}{\beta \cdot Q \cdot V_{N}\left(\lambda_{1}-\lambda_{2}\right)}\right) e^{\lambda_{1} \cdot t} \\
& -E R_{f}\left(\frac{\lambda_{2} \cdot V_{N}+\beta}{\beta}\right)\left(\frac{\beta \cdot Q+\lambda_{1} \cdot V_{N}(\beta+Q)}{\beta \cdot Q \cdot V_{N}\left(\lambda_{1}-\lambda_{2}\right)}\right) e^{\lambda_{2} \cdot t},
\end{aligned}
$$

where $C_{N F}$ and $C_{F F}$ are the concentrations predicted respectively for chefs and helpers at time $t, V_{N}$ and $V_{F}$ are respectively as the volume of near-field and far-field, $\beta$ is the air exchange rate between near-field and far-field, and $\lambda_{1}$ and $\lambda_{2}$ respectively represent the air turnover rates of near-field and far-field (in $\mathrm{min}^{-1}$ ).

\section{RESULTS AND DISCUSSION}

\section{PAH Emission Rates}

Table 2 shows the emission rates (or the generation rates) of the gas-phase PAHs, particle-phase PAHs, LMWPAH, MMW-PAH, HMW-PAH and total-BaP eq $_{\text {for the test }}$ cooking conditions. Results show that emission rates of the gas-phase PAHs and particle-phase PAHs were $1.45 \times$

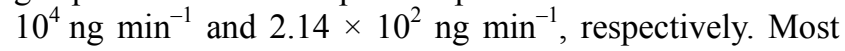

generated PAHs were in the form of the gas-phase (98.5\%) and were mainly contributed by LMW-PAHs (i.e., PAHs with 2-3 benzene rings). It is known that PAHs can be generated from cooking processes because of the incomplete combustion or pyrolysis of organic compounds containing hydrogen and carbon. Since temperatures involved in the selected cooking processes is quite low (i.e., $200^{\circ} \mathrm{C}$ ) which can only provide very limited power for the formation of PAHs, it is not so surprising to see the dominance of LMW-PAHs (especially naphthalene) in the emitted PAHs. The above inference can also be supported by many cooking-related studies (Schauer et al., 1999, 2002; McDonald et al., 2003; Sjaastad et al., 2010). However, the naphthalene emission rates of the above studies (range $=$ 127-588 $\mu \mathrm{g} \mathrm{min}{ }^{-1}$ ) were much higher than those found in the present study due to the involved cooking food weights for those of formers $(12.5-68 \mathrm{~kg}$ ) was much higher than that of the latter $(2.7 \mathrm{~kg})$. The above inference can be further supported by the comparable emission factors obtained from those of the formers $\left(4.5-16.7 \mu \mathrm{g} \mathrm{min}^{-1} \mathrm{~kg}^{-1}\right)$ and the latter $\left(5.4 \mu \mathrm{g} \mathrm{min} \mathrm{mg}^{-1}\right)$.

For particle-phase PAHs, the emission rates of LMW-, MMW-, and HMW-PAHs were $8.97 \times 10^{1}, 1.14 \times 10^{2}$, $1.00 \times 10^{1} \mathrm{ng} \mathrm{min}^{-1}$, respectively. PAHs with 3-4 benzene

\begin{tabular}{|c|c|c|c|c|c|c|}
\hline \multirow{3}{*}{ PAHs species } & \multicolumn{3}{|c|}{ Gas-phase } & \multicolumn{3}{|c|}{ Particle-phase } \\
\hline & Mean & SD & & Mean & SD & \\
\hline & $\left(\right.$ ng $\left.\min ^{-1}\right)$ & $\left(\right.$ ng $\left.\min ^{-1}\right)$ & Percentage & $\left(\mathrm{ng} \min ^{-1}\right)$ & $\left(n g \min ^{-1}\right)$ & Percentage \\
\hline Naphthalene & $1.12 \times 10^{4}$ & $6.68 \times 10^{2}$ & $77.17 \%$ & 5.10 & 1.41 & $2.38 \%$ \\
\hline Acenapthylene & $2.08 \times 10^{3}$ & $3.68 \times 10^{2}$ & $14.38 \%$ & 3.28 & $9.30 \times 10^{-1}$ & $1.54 \%$ \\
\hline Acenapthene & $1.02 \times 10^{2}$ & $2.08 \times 10^{1}$ & $0.71 \%$ & $8.30 \times 10^{-1}$ & $1.70 \times 10^{-1}$ & $0.39 \%$ \\
\hline Fluorene & $3.36 \times 10^{2}$ & $6.50 \times 10^{1}$ & $2.32 \%$ & $7.10 \times 10^{-1}$ & $4.20 \times 10^{-1}$ & $0.33 \%$ \\
\hline Phenanthrene & $4.88 \times 10^{2}$ & $9.03 \times 10^{1}$ & $3.37 \%$ & $4.62 \times 10^{1}$ & $1.13 \times 10^{1}$ & $21.62 \%$ \\
\hline Anthracene & $2.98 \times 10^{2}$ & $6.20 \times 10^{1}$ & $2.06 \%$ & $3.35 \times 10^{1}$ & 7.49 & $15.68 \%$ \\
\hline Fluoranthene & ND & -- & - & $5.77 \times 10^{1}$ & $1.18 \times 10^{1}$ & $27.00 \%$ \\
\hline Pyrene & ND & -- & -- & $4.76 \times 10^{1}$ & $1.01 \times 10^{1}$ & $22.24 \%$ \\
\hline Benzo(a)anthracene & ND & -- & -- & 4.17 & $8.30 \times 10^{-1}$ & $1.95 \%$ \\
\hline Chrysene & ND & -- & -- & 4.68 & $9.40 \times 10^{-1}$ & $2.19 \%$ \\
\hline Cyclopenta(c,d)pyrene & ND & -- & -- & 4.25 & 1.00 & $1.99 \%$ \\
\hline Benzo(b)fluoranthrene & ND & -- & -- & 1.26 & $2.60 \times 10^{-1}$ & $0.59 \%$ \\
\hline Benzo(k)fluoranthrene & ND & -- & -- & $8.40 \times 10^{-1}$ & $1.70 \times 10^{-1}$ & $0.39 \%$ \\
\hline Benzo(e)pyrene & ND & -- & -- & 1.02 & $2.50 \times 10^{-1}$ & $0.48 \%$ \\
\hline Benzo(a)pyrene & ND & -- & -- & 1.76 & $5.00 \times 10^{-1}$ & $0.82 \%$ \\
\hline Perylene & ND & -- & -- & ND & -- & -- \\
\hline Dibenz(a,h)anthracene & ND & -- & -- & ND & -- & -- \\
\hline Indeno( $1,2,3,-$ cd $)$ pyrene & ND & -- & -- & ND & -- & -- \\
\hline Benzo(b)chrysene & ND & -- & -- & ND & -- & -- \\
\hline Benzo(g,h,i)perylene & ND & -- & -- & $8.90 \times 10^{-1}$ & $1.80 \times 10^{-1}$ & $0.42 \%$ \\
\hline Coronene & ND & -- & -- & ND & -- & -- \\
\hline LMW-PAHs & $1.45 \times 10^{4}$ & $9.24 \times 10^{1}$ & $100 \%$ & $8.97 \times 10^{1}$ & $1.80 \times 10^{1}$ & $41.94 \%$ \\
\hline MMW-PAHs & ND & -- & -- & $1.14 \times 10^{2}$ & $2.35 \times 10^{1}$ & $53.38 \%$ \\
\hline HMW-PAHs & ND & -- & -- & $1.00 \times 10^{1}$ & 2.29 & $4.68 \%$ \\
\hline Total-PAHs & $1.45 \times 10^{4}$ & $1.03 \times 10^{3}$ & $98.55 \%$ & $2.14 \times 10^{2}$ & $4.35 \times 10^{1}$ & $1.45 \%$ \\
\hline Total-BaP & $3.36 \times 10^{1}$ & 5.02 & $90.53 \%$ & 3.52 & $8.90 \times 10^{-1}$ & $9.47 \%$ \\
\hline
\end{tabular}
rings (i.e., MMW-PAHs) were found to be the most dominant

Table 2. PAHs emission rates of the gas-phase and particle phase $(n=6)$.

ND: non-detected. 
compounds, which accounted for $53.38 \%$ of particle-phase PAHs. Similar results can also be found in other studies (Rogge et al., 1991; McDonald et al., 2003; Saito et al., 2014). They found that particle-phase PAHs contain mainly 3-4 ringed compounds, and the two compounds of fluoranthene (FL) and pyrene (Pyr) were found with the highest fractions.

Although particle-phase PAHs accounted for only $1.5 \%$ of the total-PAH emissions, a higher contribution (9.5\%) to the total- $\mathrm{BaP}_{\mathrm{eq}}$ emission rates was found in the present study. The above result is not so surprising because MMWand HMW-PAHs are the most dominant compounds in particle-phase PAHs, and which compounds are known with higher TEFs.

\section{Capture Efficiency and Fugitive Emission Rates}

For the purpose of estimating cooks' exposures, PAH emission rates (or generation rates; $G$ ) should be replaced by fugitive emission rates $\left(E R_{f}\right)$. Therefore, the estimation of hood capture efficiencies $(\varepsilon)$ become essential to meet the above purpose. In the present study, the heat source power $(E)$, exhaust flow rate $\left(\mathrm{q}_{\mathrm{f}}\right)$, exhaust hood height $(\mathrm{H})$, and diameter of the heat source $(\mathrm{D}$, using equivalent surface diameter) were found to be $0.7 \mathrm{~m}, 2000 \mathrm{~W}$, and $0.242 \mathrm{~m}$, respectively. Based on Eq. (4), the capture efficiencies $(\varepsilon)$ of the exhaust hood were found to be $39.1 \%, 54.7 \%$, and $76.5 \%$ for three designated exhaust flow rates of 2.64 , 3.69 , and $5.16 \mathrm{~m}^{3} \mathrm{~min}^{-1}$, respectively. The above captured efficiencies were quite comparable to those obtained from Yik and Au (2002) (i.e., 39100\%).

The obtained capture efficiencies, together with the obtained emission rates $(\mathrm{G})$ (Table 2) can be used to estimate the fugitive emission rates $\left(E R_{f}\right)$ using Eq. (2). The resultant $E_{\mathrm{f}}$ values for the exhaust flow rates $(Q)$ set at 2.64, 3.69, and $5.16 \mathrm{~m}^{3} \mathrm{~min}^{-1}$ for the total-PAHs were found to be 8.95 $\times 10^{3}, 6.66 \times 10^{3}$, and $3.46 \times 10^{3} \mathrm{ng} \mathrm{min}^{-1}$, respectively; those for the gas-phase PAHs were $8.82 \times 10^{3}, 6.57 \times 10^{3}$, and $3.41 \times 10^{3} \mathrm{ng} \mathrm{min}^{-1}$, respectively; those for the particle-phase PAHs were $1.30 \times 10^{2}, 9.69 \times 10^{1}$, and $5.03 \times 10^{1} \mathrm{ng} \mathrm{min}^{-1}$, respectively; and those for the total- $\mathrm{BaP}_{\mathrm{eq}}$ were $2.26 \times 10^{1}$,

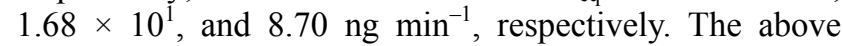
results were not so surprising since the increase in the exhaust flow rates $(Q)$ would result in the increase in the capture efficiencies $(\varepsilon)$, which leads to the decrease in the fugitive emission rates $\left(E R_{f}\right)$.

\section{Predicted PAH Exposure Concentrations}

Table 3 shows the predicted PAH exposure concentrations (including the gas-phase PAHs, particle-phase PAHs, LMW-PAH, MMW-PAH, HMW-PAH and total-BaP eq $_{\text {) for }}$ all workers (i.e., $C_{W M R}$ representing predicted PAH exposure concentrations for workers in both NF and FF), chefs' exposure concentrations (i.e., $C_{N F}$ representing the predicted concentrations for workers in the NF), and helpers' exposure concentrations (i.e., $C_{F F}$ representing the predicted concentrations for workers in the FF) under three designated exhaust hood flow rates (i.e., $2.64 \mathrm{~m}^{3} \mathrm{~min}^{-1}, 3.69 \mathrm{~m}^{3} \mathrm{~min}^{-1}$, and $5.16 \mathrm{~m}^{3} \mathrm{~min}^{-1}$ ) using Eqs. (5), (6), and (7), respectively. The average random airspeed $(\beta)$ used in the NF/FF model

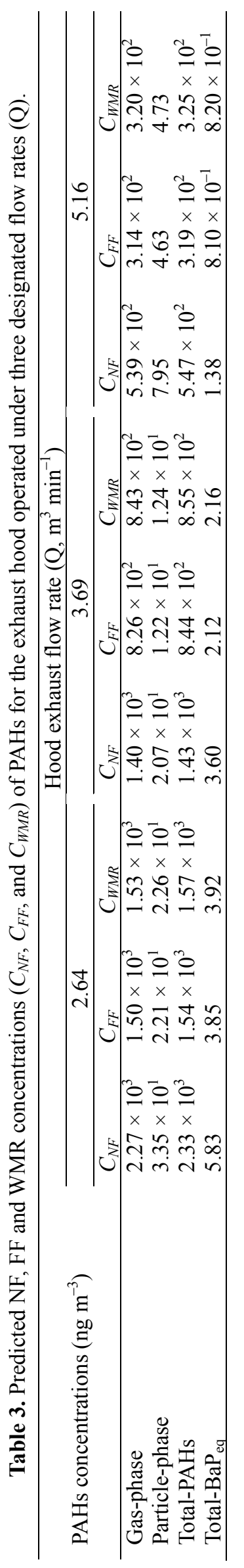


was measured using an anemometer (TSI 9565-X, TSI Inc., MN, USA) with a thermo-anemometer probe (TSI 966 , TSI Inc., MN, USA). In the present study, $\beta$ was 0.03 , 0.03 , and $0.04 \mathrm{~m} \mathrm{~s}^{-1}$ when the exhaust hood flow rates were set at $2.64,3.69$, and $5.16 \mathrm{~m}^{3} \mathrm{~min}^{-1}$, respectively. Results show that PAH concentrations (including the gasphase PAHs, particle-phase PAHs, LMW-PAH, MMW$\mathrm{PAH}, \mathrm{HMW}-\mathrm{PAH}$ and total- $\mathrm{BaP}_{\mathrm{eq}}$ ) in magnitude for the three predicted results were: $C_{N F}>C_{W M R}>C_{F F}$ (Table 3). Since workers in the NF were closer to the emission source than those in FF, the predicted PAH exposure concentrations of $C_{N F}$ and hence were higher than that of $C_{F F}$. On the other hand, $C_{W M R}$ represents the emitted PAHs being uniformly distributed in the test room, and hence it can be expected that the magnitudes of $C_{W M R}$ fall between $C_{N F}$ and $C_{F F}$.

\section{Measured PAH Exposure Concentrations}

Table 4 shows the measured PAH exposure concentrations for all workers (i.e., $C_{T}$, including sampling results obtained from both chef-zone (CZ) and helper-zone (HZ)), chef exposure concentrations (i.e., $C_{C Z}$, sampling results obtained from $\mathrm{CZ}$ ) and helper exposure concentrations (i.e., $C_{H Z}$, sampling results obtained from $\mathrm{HZ}$ ) under three designated exhaust hood flow rate conditions (i.e., $2.64 \mathrm{~m}^{3} \mathrm{~min}^{-1}$, $3.69 \mathrm{~m}^{3} \mathrm{~min}^{-1}, 5.16 \mathrm{~m}^{3} \mathrm{~min}^{-1}$ ). Results show that LMW-PAHs dominated in all the measured total-PAH concentrations, including $C_{T}, C_{C Z}$ and $C_{H Z}$. The above results were consistent with that of fugitive PAH emission results. In particular, most of the total PAH concentration was contributed by the naphthalene $(\sim 90 \%)$, which was also consistent with the results reported by Sjaastad et al. (2010). Though the measured PAH concentrations for $C_{C Z}$ were slightly higher than that of $C_{H Z}$, but no significant difference could be found in the present study $(\mathrm{P}>0.05)$. Therefore, workers in the test kitchen may have very similar PAH exposures regardless of their locations. This could be explained by the circulation of airflow in the test room. In principle, cooking oil fumes could be first lifted by the thermal draft, then partly removed by the exhaust hood, and the rest reach the ceiling of the kitchen, then turn downward to the floor, and finally combine with the new generated cooking oil fumes, and then repeat the above cycle. As a result, a well-mixed condition was found in the test room which leads to no significant difference in PAH concentration between $C_{C Z}$ and $C_{H Z}$.

Considering there was no significant difference between the $C_{C Z}$ and $C_{H Z}$, both results were combined to describe the overall PAH concentrations $\left(C_{T}\right)$ in the test room. For $C_{T}$, Table 4 also shows that the mean total-PAHs were increased from $1.36 \times 10^{2}$ to $2.93 \times 10^{2} \mathrm{ng} \mathrm{m}^{-3}$ as exhaust hood flow rates decreased from $5.16 \mathrm{~m}^{3} \mathrm{~min}^{-1}$ to 2.64 $\mathrm{m}^{3} \mathrm{~min}^{-1}$. Obviously, the above results can be explained by the fact that the increase in the exhaust hood flow rates would result in the increases in the capture efficiencies.

Table 4 also shows that all measured PAH exposure concentrations (i.e., $C_{C Z}, C_{H Z}$, and $C_{T}$ ) were $\sim 5$ times in magnitude less than the corresponding predicted exposure concentrations (i.e., $C_{N F}, C_{F F}$, and $C_{W M R}$ ). Here, it should be noted that the predictions of $C_{N F}, C_{F F}$, and $C_{W M R}$ assumes well-mixed PAH concentrations in the designated zones. However, the thermal draft effect would result in higher concentrations accumulated at the ceiling, and decreased as the height decreased. The above inference is supported by our findings (i.e., $C_{C Z}, C_{H Z}$, and $C_{T}$ were much lower than that of the corresponding $C_{N F}, C_{F F}$, and $\left.C_{W M R}\right)$. In addition, the stratified concentration scenario also suggests the concentrations at the same height could be very similar. Since $C_{C Z}, C_{H Z}$, and $C_{T}$ were measured at the same height (i.e., $1.5 \mathrm{~m}$ in height from the floor), no significant difference in their measured results could be theoretically plausible.

Table 4. Measured chef, helper and all worker concentrations $\left(C_{C Z}, C_{H Z}\right.$, and $\left.C_{T}\right)$ of PAHs for the exhaust hood operated under three designated flow rates (Q).

\begin{tabular}{|c|c|c|c|c|c|c|}
\hline $\begin{array}{l}\text { Hood exhaust flow rate } \\
\left(\mathrm{Q}, \mathrm{m}^{3} \mathrm{~min}^{-1}\right)\end{array}$ & $\begin{array}{l}\text { PAHs concentrations } \\
\left(\mathrm{ng} \mathrm{m}^{-3}\right)\end{array}$ & LMW-PAHs & MMW-PAHs & HMW-PAHs & Total-PAHs & Total- $\mathrm{BaP}_{\mathrm{eq}}$ \\
\hline \multirow[t]{6}{*}{$2.64(\mathrm{n}=3)$} & $\mathrm{C}_{\mathrm{CZ}}$ & $2.92 \times 10^{2}$ & 1.97 & $9.65 \times 10^{-1}$ & $2.95 \times 10^{2}$ & $7.90 \times 10^{-1}$ \\
\hline & SD & $1.42 \times 10^{1}$ & $8.80 \times 10^{-1}$ & $4.30 \times 10^{-1}$ & $1.45 \times 10^{1}$ & $1.10 \times 10^{-1}$ \\
\hline & $\mathrm{C}_{\mathrm{HZ}}$ & $2.89 \times 10^{2}$ & 1.25 & $6.75 \times 10^{-1}$ & $2.91 \times 10^{2}$ & $7.47 \times 10^{-1}$ \\
\hline & SD & $3.08 \times 10^{1}$ & $5.20 \times 10^{-1}$ & $2.80 \times 10^{-1}$ & $3.11 \times 10^{1}$ & $9.00 \times 10^{-2}$ \\
\hline & $\mathrm{C}_{\mathrm{T}}$ & $2.90 \times 10^{2}$ & 1.61 & $8.20 \times 10^{-1}$ & $2.93 \times 10^{2}$ & $7.64 \times 10^{-1}$ \\
\hline & SD & $2.11 \times 10^{1}$ & $6.20 \times 10^{-1}$ & $3.20 \times 10^{-1}$ & $2.11 \times 10^{1}$ & $9.00 \times 10^{-2}$ \\
\hline \multirow[t]{6}{*}{$3.69(n=3)$} & $\mathrm{C}_{\mathrm{CZ}}$ & $1.61 \times 10^{2}$ & $8.03 \times 10^{-1}$ & $4.78 \times 10^{-1}$ & $1.62 \times 10^{2}$ & $5.20 \times 10^{-1}$ \\
\hline & SD & $3.10 \times 10^{1}$ & $2.40 \times 10^{-1}$ & $1.40 \times 10^{-1}$ & $3.07 \times 10^{1}$ & $5.00 \times 10^{-2}$ \\
\hline & $\mathrm{C}_{\mathrm{HZ}}$ & $1.52 \times 10^{2}$ & 1.04 & $5.34 \times 10^{-1}$ & $1.54 \times 10^{2}$ & $5.87 \times 10^{-1}$ \\
\hline & SD & $1.95 \times 10^{1}$ & $1.60 \times 10^{-1}$ & $8.00 \times 10^{-2}$ & $1.93 \times 10^{1}$ & $7.00 \times 10^{-2}$ \\
\hline & $\mathrm{C}_{\mathrm{T}}$ & $1.57 \times 10^{2}$ & $9.19 \times 10^{-1}$ & $5.06 \times 10^{-1}$ & $1.58 \times 10^{2}$ & $5.51 \times 10^{-1}$ \\
\hline & SD & $2.53 \times 10^{1}$ & $2.00 \times 10^{-1}$ & $1.10 \times 10^{-1}$ & $2.50 \times 10^{1}$ & $5.00 \times 10^{-2}$ \\
\hline \multirow[t]{6}{*}{$5.16(\mathrm{n}=3)$} & $\mathrm{C}_{\mathrm{CZ}}$ & $1.40 \times 10^{2}$ & $7.28 \times 10^{-1}$ & $3.85 \times 10^{-1}$ & $1.41 \times 10^{2}$ & $3.59 \times 10^{-1}$ \\
\hline & SD & $1.37 \times 10^{1}$ & $2.00 \times 10^{-1}$ & $1.10 \times 10^{-1}$ & $1.34 \times 10^{1}$ & $1.00 \times 10^{-2}$ \\
\hline & $\mathrm{C}_{\mathrm{HZ}}$ & $1.30 \times 10^{2}$ & $7.00 \times 10^{-1}$ & $3.54 \times 10^{-1}$ & $1.31 \times 10^{2}$ & $3.45 \times 10^{-1}$ \\
\hline & SD & $2.53 \times 10^{1}$ & $2.40 \times 10^{-1}$ & $1.20 \times 10^{-1}$ & $2.56 \times 10^{1}$ & $1.20 \times 10^{-1}$ \\
\hline & $\mathrm{C}_{\mathrm{T}}$ & $1.35 \times 10^{2}$ & $7.14 \times 10^{-1}$ & $3.70 \times 10^{-1}$ & $1.36 \times 10^{2}$ & $3.52 \times 10^{-1}$ \\
\hline & SD & $1.01 \times 10^{1}$ & $2.20 \times 10^{-1}$ & $1.10 \times 10^{-1}$ & $1.02 \times 10^{1}$ & $6.00 \times 10^{-2}$ \\
\hline
\end{tabular}




\section{Proposal for Predicting Workers'PAH Exposure Concentrations}

Since the measured PAH concentrations of $C_{C Z}$ and $C_{H Z}$ were not significantly different, the WMR model was selected to serve as a basis for predicting the PAH exposure concentrations. Fig. 3 shows the relationship between WMR model predicted results (i.e., $C_{W M R}$ ) and field measured results (i.e., $C_{T}$ ) on the gas-phase PAHs, particlephase PAHs, total-PAHs, and total- $\mathrm{BaP}_{\text {eq }}$ basis. High $\mathrm{R}^{2}$ were consistently found in the gas-phase PAHs, particlephase PAHs, total-PAHs, and total- $\mathrm{BaP}_{\text {eq }}(0.857,0.711$, 0.860 , and 0.92 , respectively). The above results suggest that the WMR model can be used as a basis for predicting the PAH exposure concentrations of cooking workers.

Comparable $\mathrm{R}^{2}$ and regression equations were obtained for the gas-phase PAHs and total-PAHs, which obviously can be explained by the fact that the total-PAHs were dominated by gas-phase PAHs. The particle-phase PAHs were found with the lowest $\mathrm{R}^{2}$, which indicated that the variation in the particle-phase PAHs was higher than that of others. The regression equation for the total- $\mathrm{BaP}_{\mathrm{eq}}$ concentrations much comparable to that of particle-phase PAHs, rather than gas-phase PAHs. The above results can be explained by the high TEFs assigned for MMW-PAHs and HMW-PAHs (i.e., main contributors in particle-phase PAHs), and variation of particle-phase PAH was mainly contributed by the LMW-PAHs.

Yet, it is true that the resultant regression equations might be not universally applicable. The approach proposed by the present study provides a possibility for establishing a long-term exposure databank for cooking industries for less constraints in both samplings and sample analyses.

\section{CONCLUSIONS}

Most of the generated PAHs were gaseous and low in molecular weight. Although particle-phase PAHs accounted for a very low fraction of the total-PAH emissions, they contributed a larger share to the total- $\mathrm{BaP}_{\mathrm{eq}}$ emission rates in the present study. The capture efficiencies of the exhaust hood fell in the range of $39.1-76.5 \%$, indicating that fugitive PAH emissions are theoretically plausible. All of the measured PAH exposure concentrations were $\sim 5$ times less in magnitude than the corresponding predicted exposure concentrations. Since $C_{C Z}, C_{H Z}$, and $C_{T}$ were measured at the same height, the lack of a significant difference between their measured concentrations can be explained by the circulation effect. On the other hand, the values for (a)

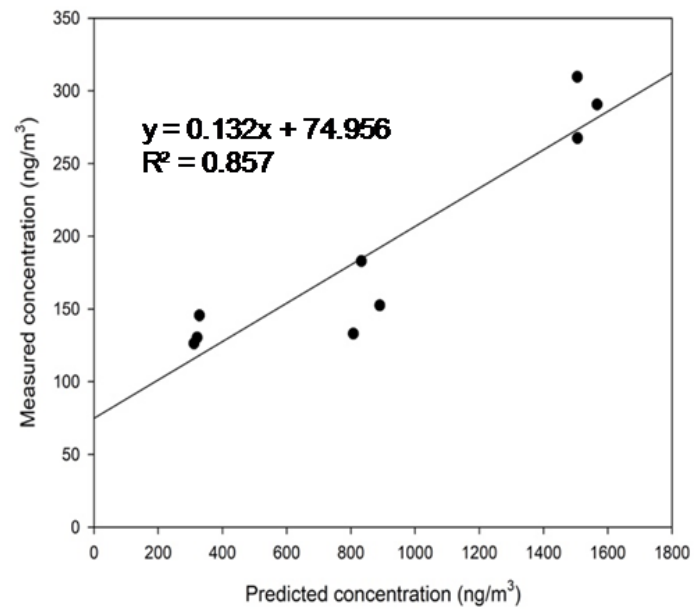

(c)

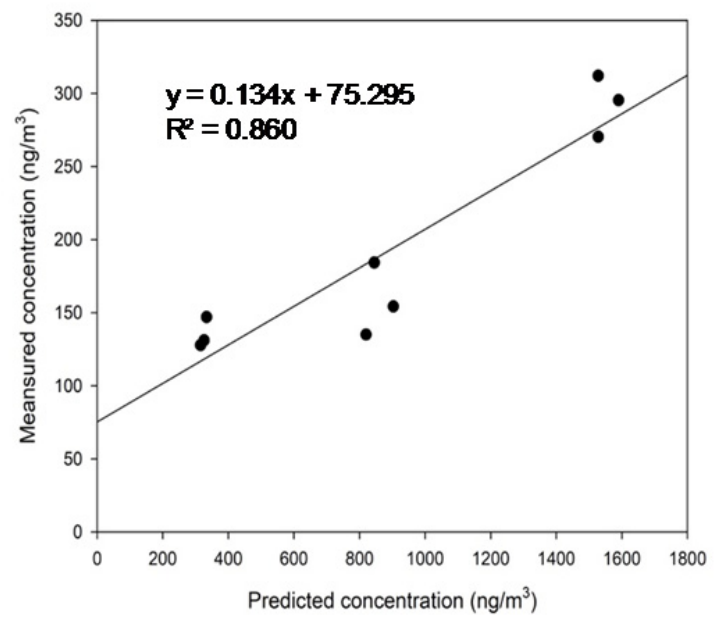

(b)

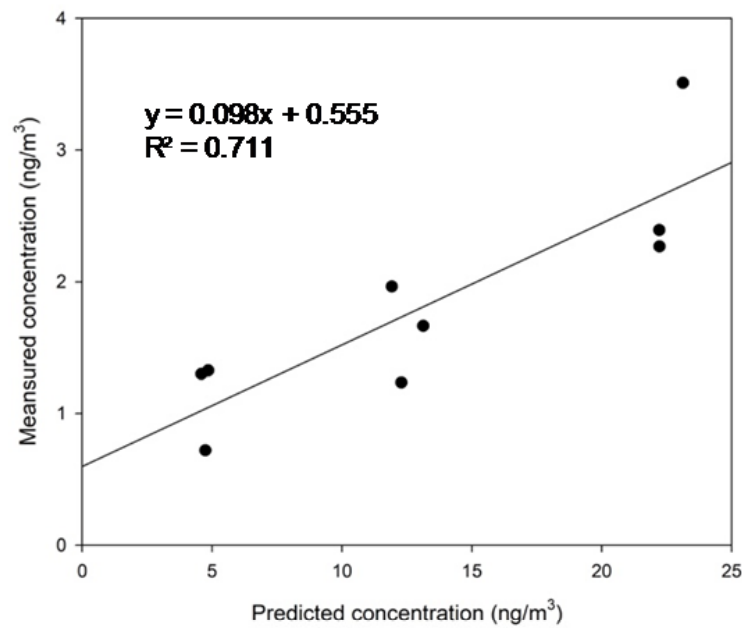

(d)

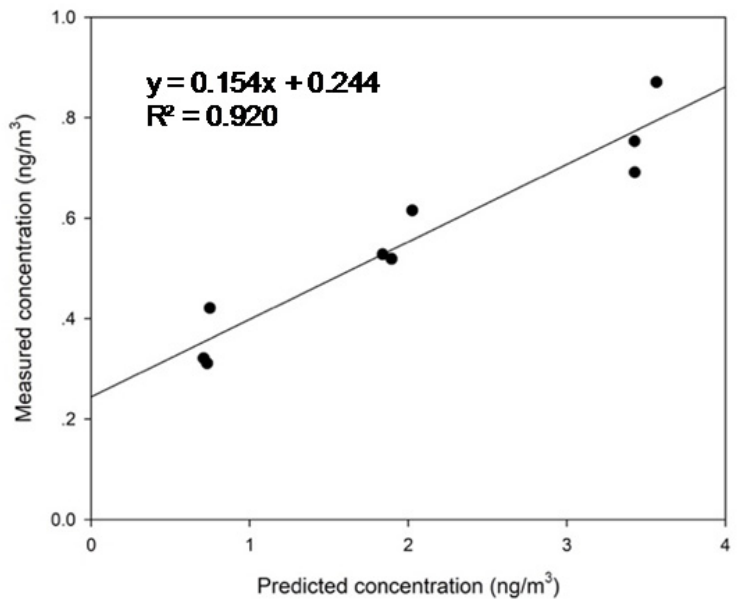

Fig. 3. Relationships between measured $(y)$ and predicted $(x)$ exposure concentrations for the (a) gas-phase PAHs, (b) particle-phase PAHs, (c) total-PAHs, and (d) total-BaP $\mathrm{P}_{\mathrm{eq}}(\mathrm{n}=9)$. 
$C_{C Z}, C_{H Z}$, and $C_{T}$ were much lower than those for $C_{N F}, C_{F F}$, and $C_{W M R}$, which suggests that the PAH concentrations might have been stratified in the atmosphere of the test room. The relationship between the WMR model predicted results and the field measured results exhibited a high $\mathrm{R}^{2}$, indicating that the WMR model can serve as a reliable basis for predicting the PAH exposure concentrations of cooking workers. Although the resultant regression equations may not be universally applicable, the present study has proposed a suitable approach to establishing a long-term exposure databank for cooking industries with fewer constraints on both sampling and sample analysis.

\section{ACKNOWLEDGMENT}

The authors would like to thank Ministry of Science and Technology (MOST) in Taiwan for funding this research work. The co-author Yu-Cheng Chen contributed equivalent to the correspondence author.

\section{REFERENCES}

Abdullahi, K.L., Delgado-Saborit, J.M. and Harrison, R.M. (2013). Emissions and indoor concentrations of particulate matter and its specific chemical components from cooking: A review. Atmos. Environ. 71: 260-294.

AIHA (2009). Mathematical models for estimating occupational exposure to chemicals, 2nd deition. American Industrial Hygiene Association, Washington, USA.

Chiang, T.A., Wu, P.F. and Ko, Y.C. (1998). Prevention of exposure to mutagenic fumes produced by hot cooking oil in taiwanese kitchens. Environ. Mol. Mutagen. 31: 92-96.

Culp, S.J., Gaylor, D.W., Sheldon, W.G., Goldstein, L.S. and Beland, F.A. (1998). A comparison of the tumors induced by coal tar and benzo[a]pyrene in a 2-year bioassay. Carcinogenesis 19: 117-124.

Gaffney, S., Moody, E., McKinley, M., Knutsen, J., Madl, A. and Paustenbach, D. (2008). Worker exposure to methanol vapors during cleaning of semiconductor wafers in a manufacturing setting. J. Occup. Environ. Hyg. 5: 313-324.

Gao, J., Cao, C.S., Wang, L., Song, T.H., Zhou, X., Yang, J. and Zhang, X. (2013). Determination of size-dependent source emission rate of cooking-generated aerosol particles at the oilheating stage in an experimental kitchen. Aerosol Air Qual. Res. 13: 488-496.

IARC (2010). Household use of solid fuels and hightemperature frying, Cancer, International Agency for Research on Cancer, Lyon.

Kim, S.Y., Sheppard, L. and Kim, H. (2009). Health effects of long-term air pollution: Influence of exposure prediction methods. Epidemiology 20: 442-450.

Larsen, J.C. and Larsen, P.B. (1998). Chemical carcinogens. In Air pollution and health, Hester, R.E. and Harrison, R.M. (Eds.), The Royal Society of Chemistry, Cambridge, UK.

Li, C.T., Lin, Y.C., Lee, W.J. and Tsai, P.J. (2003).
Emission of polycyclic aromatic hydrocarbons and their carcinogenic potencies from cooking sources to the urban atmosphere. Environ. Health Perspect. 111: 483.

Li, Y. and Delsante, A. (1996). Derivation of capture efficiency of kitchen range hoods in a confined space. Build. Environ. 31: 461-468.

Lunden, M.M., Delp, W.W. and Singer, B.C. (2015). Capture efficiency of cooking-related fine and ultrafine particles by residential exhaust hoods. Indoor Air 25: 45-58.

Malcolm, H. and Dobson, S. (1994). The calculation of an environmental assessment level (EAL) for atmospheric PAHs using relative potencies, Department of the Environment, London, UK.

McDonald, J.D., Zielinska, B., Fujita, E.M., Sagebiel, J.C., Chow, J.C. and Watson, J.G. (2003). Emissions from charbroiling and grilling of chicken and beef. J. Air Waste Manage. Assoc. 53: 185-194.

Mi, H.H., Liao, W.T., Chang, H.C., Chen, S.J., Lin, C.C. and Hsieh, L.T. (2014). Optical emission spectroscopy in cooking exhaust from a wet scrubber/atmospheric plasma reactor. Aerosol Air Qual. Res. 10: 1665-1674.

Nicas, M. (2006). The near field/far field (two-box) model with a constant contamination emission rate. In Mathematical models for estimating occupational exposure to chemicals. Keil, C.B., Simmons, C.E. and Anthony, T.R. (Eds.), American Industrial Hygiene Association (AIHA), Fairfax, VA, USA, pp. 47-52.

Nicas, M., Plisko, M.J. and Spencer, J.W. (2006). Estimating benzene exposure at a solvent parts washer. J. Occup. Environ. Hyg. 3: 284-291.

Nisbet, I.C. and LaGoy, P.K. (1992). Toxic equivalency factors (TEFs) for polycyclic aromatic hydrocarbons (PAHs). Regul. Toxicol. Pharm. 16: 290-300.

Reinke, P.H. and Keil, C.B. (2006). Well-mixed box model. In Mathematical models for estimating occupational exposure to chemicals, American Industrial Hygiene Association (AIHA), Fairfax, VA, USA, pp. $23-31$.

Popiołek, Z., Trzeciakiewicz, Z. and Mierzwinski, S. (1998). Improvement of a plume volume flux calculation method. International conference on air distribution in rooms. Proceedings ROOMVENT '98, Stockhom, Sweden, Vol. 1, pp. 423-430.

Purcaro, G., Navas, J.A., Guardiola, F., Conte, L.S. and Moret, S. (2006). Polycyclic aromatic hydrocarbons in frying oils and snacks. J. Food Protect. 69: 199-204.

Rogge, W.F., Hildemann, L.M., Mazurek, M.A., Cass, G.R. and Simoneit, B.R. (1991). Sources of fine organic aerosol. 1. Charbroilers and meat cooking operations. Environ. Sci. Technol. 25: 1112-1125.

Saito, E., Tanaka, N., Miyazaki, A. and Tsuzaki, M. (2014). Concentration and particle size distribution of polycyclic aromatic hydrocarbons formed by thermal cooking. Food Chem. 153: 285-291.

Schauer, J.J., Kleeman, M.J., Cass, G.R. and Simoneit, B.R. (1999). Measurement of emissions from air pollution sources. 1. $\mathrm{C}_{1}$ through $\mathrm{C}_{29}$ organic compounds from meat charbroiling. Environ. Sci. Technol. 33: 1566-1577. 
Schauer, J.J., Kleeman, M.J., Cass, G.R. and Simoneit, B.R. (2002). Measurement of emissions from air pollution sources. 4. $\mathrm{C}_{1}-\mathrm{C}_{27}$ organic compounds from cooking with seed oils. Environ. Sci. Technol. 36: 567-575.

See, S.W. and Balasubramanian, R. (2006). Physical characteristics of ultrafine particles emitted from different gas cooking methods. Aerosol Air Qual. Res. 6: 82-92.

See, S.W. and Balasubramanian, R. (2008). Chemical characteristics of fine particles emitted from different gas cooking methods. Atmos. Environ. 42: 8852-8862.

Siegmann, K. and Sattler, K. (1996). Aerosol from hot cooking oil, a possible health hazard. J. Aerosol Sci. 27: S493-S494.

Sjaastad, A.K., Jørgensen, R.B. and Svendsen, K. (2010). Exposure to polycyclic aromatic hydrocarbons (PAHs), mutagenic aldehydes and particulate matter during pan frying of beefsteak. Occup. Environ. Med. 67: 228-232.

Wang, G., Cheng, S., Wei, W., Wen, W., Wang, X. and Yao, S. (2015). Chemical characteristics of fine particles emitted from different chinese cooking styles. Aerosol Air Qual. Res. 15: 2357-2366.

Yik, F. and Au, P. (2002). Flow rate and capture efficiency of domestic kitchen exhaust hoods for chinese households. Int. J. Archit. Sci. 3: 125-134.

Zhang, S., Peng, S.C., Chen, T.H. and Wang, J.Z. (2015). Evaluation of inhalation exposure to carcinogenic $\mathrm{PM}_{10^{-}}$ bound pahs of people at night markets of an urban area in a metropolis in eastern china. Aerosol Air Qual. Res. 15: 1944-1954.

Zhu, L.H. and Wang, J. (2003). Sources and patterns of polycyclic aromatic hydrocarbons pollution in kitchen air, China. Chemosphere 50: 611-618.

Received for review, September 17, 2018

Revised, November 27, 2018

Accepted, December 11, 2018 